\title{
Strategies of a parasite of the ant-Acacia mutualism
}

\author{
Lars W. Clement • Stephan C. W. Köppen • \\ Willi A. Brand • Martin Heil
}

Received: 25 March 2007 /Revised: 25 September 2007 / Accepted: 6 November 2007 / Published online: 29 November 2007

(C) Springer-Verlag 2007

\begin{abstract}
Mutualisms can be exploited by parasites - species that obtain resources from a partner but provide no services. Though the stability of mutualisms in the presence of such parasites is under intensive investigation, we have little information on life history traits that allow a species to be a successful mutualist or rather a parasite, particularly in cases where both are closely related. We studied the exploitation of Acacia myrmecophytes by the ant, Pseudomyrmex gracilis, contrasting with the mutualistic ant Pseudomyrmex ferrugineus. P. gracilis showed no host-defending behavior and had a negative effect on plant growth. By preventing the mutualist from colonization, $P$. gracilis imposes opportunity
\end{abstract}

Communicated by L. Sundström

L. W. Clement $\cdot$ M. Heil $(\bowtie)$

Department of Bioorganic Chemistry,

Max Planck Institute for Chemical Ecology,

Hans Knöll Straße 8,

07745 Jena, Germany

e-mail: mheil@ira.cinvestav.mx

S. C. W. Köppen · M. Heil

Department of General Botany-Plant Ecology,

University of Duisburg-Essen,

FB BioGeo, Universitäts straße 5,

45117 Essen, Germany

W. A. Brand

Department of Isotope Analysis,

Max Planck Institute of Biogeochemistry,

Hans Knöll Straße 10,

07745 Jena, Germany

\section{Heil}

Dpto. de Ingeniería Genética, CINVESTAV,

Km. 9.6 Libramiento Norte,

Irapuato, Guanajuato 36821, Mexico costs on the host plant. P. gracilis produced smaller colonies with a higher proportion of alates than did the mutualist and thus showed an " $r$-like" strategy. This appears to be possible because $P$. gracilis relies less on host-derived food resources than does the mutualist, as shown by behavioral and stable isotope studies. We discuss how this system allows the identification of strategies that characterize parasites of mutualisms.

Keywords Acacia · Ant-plant interaction · Mutualism · Parasitism $\cdot$ Stable isotopes

\section{Introduction}

Mutualisms are interactions among members of different species that lead to net fitness benefits for all partners involved. In general, mutualisms are based on the exchange of resources and services that the individual species would obtain or produce less efficiently (Bronstein 1994). As these resources can be attractive to non-mutualists as well, mutualisms are in danger of being invaded by other species, which make use of the rewards provided by a partner without rendering the respective service. Such species are termed cheaters, exploiters, or parasites of the mutualism (Bronstein 2001; Wilkinson and Sherratt 2001; Yu 2001), and the stability of mutualisms in their presence is the subject of intensive empirical and theoretical research (Gaume and McKey 1999; Hoeksema and Bruna 2000; Bronstein 2001; Yu 2001; Kiers et al. 2003; Stanton 2003; Yu et al. 2004; Edwards et al. 2006; Ferrière et al. 2007).

Some obligate mutualisms are transmitted vertically; during reproduction, the host transmits symbiont offspring to its own offspring. Such vertical transmission is known, e.g., from scale insects or aphids living symbiotically with 
certain ant species, where some mutualists are actively carried by founding ant queens during the nuptial flight (Buschinger et al. 1987; Klein et al. 1992). Vertical transmission furthermore is common in endosymbiotic mutualisms among, e.g., insects and bacteria such as Wolbachia and Blochmannia (Zientz et al. 2004, 2005). Such mutualisms are considered evolutionarily stable and, in fact, are often characterized by a high level of phylogenetic congruency among partners (Sauer et al. 2000; Clark et al. 2001).

Yet, the majority of mutualisms are transmitted horizontally; the partners must establish the interaction anew in each generation. This mode of transmission characterizes several common mutualisms such as plant pollination or dispersal by animals, mycorrhiza, or bacterial nodulation of roots and applies to both obligate and facultative mutualisms. As the partners have to rejoin at least after each reproductive event, such mutualisms are easily exploited and their evolutionary stability remains an open issue (Wilkinson and Sherratt 2001). Recently, Ferrière et al. (2007) examined the conditions under which cooperation (i.e., mutualistic behavior) can be evolutionarily stable in the presence of exploiters. However, empirical information is scarce on characteristic life history traits of exploiters and on the strategies allowing the successful exploitation of host resources.

The aim of this study is to fill this gap, using ant-plant mutualists and their parasites as a model. Obligate ant plants (myrmecophytes) gain protection from their enemies by resident ants, which are provided with nesting space and, in most cases, food rewards (Bronstein 1998; Heil and McKey 2003). They are, however, also targets for exploitation, and parasites of ant-plant mutualisms have repeatedly been described. Central American swollen thorn acacias, for example, can be inhabited by the two nondefending parasitic ant species Pseudomyrmex nigropilosus (Janzen 1975) and Camponotus planatus (Raine et al. 2004). Similar cases of ants failing to defend their host have also been described for the ant plants Leonardoxa africana ssp. africana (Gaume and McKey 1999) and Cordia alliodora (Tillberg 2004), while other types of exploitation encompass ants that castrate their plant host, i.e., that actively cut off the host plant's flowers in order to re-direct resource allocation from plant reproduction to vegetative growth (Yu and Pierce 1998; Stanton et al. 1999; Izzo and Vasconcelos 2002).

The putative parasite studied here, Pseudomyrmex gracilis, is generally considered a generalist, twig-nesting ant but has been reported to live in thorns of myrmecophytic swollen thorn acacias (Skwarra 1935; Wheeler 1942; Ward 1993). The species is part of the $P$. gracilis group and is taxonomically closely related to P. nigropilosus (Ward and Downie 2005). The mutualist used for comparison,
Pseudomyrmex ferrugineus, belongs to the P. ferrugineus group and thus forms part of a different clade of the same genus (Ward 1993). Ants of this species protect their host from herbivores and encroaching vegetation (Janzen 1966, 1974), cannot be found nesting outside of their host plants, only feed on host-derived food resources (Heil et al. 2004), and are physiologically adapted to the specific composition of extrafloral nectar secreted by their host plants (Heil et al. 2005).

Here, we test the hypothesis that $P$. gracilis parasitizes the ant-Acacia mutualism by making use of the hostderived resources without rendering a protective service, and we characterize the life history traits that distinguish it from $P$. ferrugineus. We compared the defensive behavior and the effect on host plant growth of the two ant species. As parasites of mutualisms can impose opportunity rather than direct costs (Yu and Pierce 1998), we also studied the effects of Acacia occupation by $P$. gracilis on colony founding and inhabitation by the mutualist. Furthermore, if $P$. gracilis indeed fails to protect its host plant, we should expect its nutrition and reproduction to be less dependent on its host plant than in case of $P$. ferrugineus. Putative adaptations to the different lifestyles therefore were investigated by comparing colony structures of the two ant species and by studying food use via behavioral observations and stable isotope analysis. As stable isotopes are transported in well-defined manners up the food chain, natural abundances of stable isotopes are widely used in studies of trophic structures. For example, ${ }^{13} \mathrm{C}$ is usually transported without significant quantitative change across tropic levels and thus can be used to identify an organism's main food source by comparing the organism's ${ }^{13} \mathrm{C}$ signature with that of its putative food source. ${ }^{15} \mathrm{~N}$, in contrast, is enriched in consumers due to discrimination among the different isotopes by the respective metabolic enzymes, hence clearly marking increases in trophic level (Peterson and Fry 1987; Post 2002; Thompson et al. 2005).

The type and availability of food affects the life history traits of a species and might importantly affect the trade-off between investment in reproduction and in growth or maintenance. Accordingly, Janzen (1975) hypothesized that parasitic ants which, by not protecting their host plant, live on an ephemeral resource should invest early during colony development in the production of alates. We therefore finally studied colony sizes and alate-worker ratios.

Our predictions are: (1) P. gracilis does not defend its host plant but does make use of host-derived resources (food and nesting space), and it should use external resources more than does the mutualist, $P$. ferrugineus, (2) the presence of a $P$. gracilis colony prevents colonization by $P$. ferrugineus, and (3) P. gracilis should allocate more resources to reproduction at smaller colony sizes. 


\section{Materials and methods}

Study sites, ant, and plant species

The study was conducted during several field stays (AprilMay 2004, September 2005, September 2006, and February 2007) in the state of Oaxaca, México. Most investigations were conducted on extensively used pastures approximately $15 \mathrm{~km}$ west of Puerto Escondido in the coastal area of Oaxaca ( $15^{\circ} 55.596^{\prime} \mathrm{N}$ and $97^{\circ}$ 9.118 $\mathrm{W}$, elevation $15 \mathrm{~m}$ ). Additional observations were made on a pasture on the Isthmus of Tehuantepec approximately $25 \mathrm{~km}$ north of Matias Romero, Oaxaca ( $17^{\circ} 6.020^{\prime} \mathrm{N}$ and $95^{\circ} 55.860^{\prime}$, elevation $140 \mathrm{~m}$ ). Species of myrmecophytes investigated were Acacia collinsii Safford, Acacia cornigera (L.) Willendow, Acacia hindsii Bentham, and A. chiapensis Safford (determined following Janzen 1974). Ant species considered were $P$. gracilis Roger and P. ferrugineus Smith (determined following Ward 1993). While the first survey was conducted for all four myrmecophytic Acacia species growing at our study sites, we focused the experimental part of our study on $A$. hindsii, thus controlling for the effects of host plant species.

\section{Survey of inhabitation and state of plants}

Inhabitations by the different ant species were studied at both sites in April and May 2004. We randomly selected 316 individual shrubs and scored the ant species that inhabited each plant, as defined by workers entering or leaving hollow thorns.

The effect of ant occupancy on the current state of the plant was investigated using plants that carried single colonies of one of the two ant species in September 2005. As many more plants are inhabited by $P$. ferrugineus than by $P$. gracilis, all $A$. hindsii plants inhabited only by $P$. gracilis were selected on two pastures (34 plants in total) and their state was estimated as follows: (1) the numbers of dead and living shoot tips were counted to calculate the percentage of dead tips, (2) the degree of herbivory was estimated to the nearest $10 \%$ of total leaf area missing, and (3) the level of overgrowth was estimated as the percent of total leaf area covered by other plants (ten categories, from $0=$ no contact by other plants to $10=$ plant completely overgrown by other plants). Then, the nearest plant inhabited only by $P$. ferrugineus that had a size differing by $<20 \%$ to the $P$. gracilis-inhabited plant in question was selected, and the same parameters were quantified. Differences between plants inhabited by the two ant species were tested with Wilcoxon paired tests for each of the three parameters considered.

Effects of ant occupancy on growth rate were studied from September 2006 until February 2007 (end of rainy and mid dry season) by marking $44 \mathrm{~A}$. hindsii saplings (heights 0.4-2.0 m) on one pasture. We rated the degree of dominance of ant species $i, D_{\mathrm{i}}$, on an ordinal scale as follows: $0=$ no ant of the respective species present, $1=\mathrm{a}$ single ant present, $2=$ few $(2-10)$ ants present on $<25 \%$ of leaves, $3=$ workers on $25-50 \%$ of leaves, $4=$ workers on $50-75 \%$ of leaves, $5=$ entire plant occupied or patrolled. Eight plants in the dataset hosted colonies of both species. The relative degree of dominance by $P$. gracilis is defined as the difference between the two measures: $D_{\text {diff }}=D_{\text {gracilis }}{ }^{-}$ $D_{\text {ferrugineus. }}$ The response variable, total shoot length of the plants, was measured to the nearest $5 \mathrm{~cm}$. The site was then revisited in February 2007 and the total shoot length was remeasured in order to calculate relative growth rates: (final total shoot length-initial total shoot length)/(initial total shoot length).

\section{Defensive and feeding behavior of ants}

The defensive behavior of ants was categorized for 147 colonies of $P$. ferrugineus and 60 colonies of $P$. gracilis. Each of these colonies was the only colony inhabiting the respective host plant. As the strength of the recruitment when ant colonies are disturbed is largely independent of the initial activity level and because this behavior best reflects the maximum defense intensity, we challenged the colonies by touching the plant surface with forceps. The resulting ant behavior was categorized as follows: A: workers patrolling on $>75 \%$ of leaves, rapid recruitment, and highly aggressive behavior; B: workers patrolling on $>50 \%$ of leaves, slow recruitment, aggressive behavior; $\mathrm{C}$ : workers patrolling $<50 \%$ of leaves, slow recruitment, mixed aggression and escape behavior; D: few workers patrolling, no recruitment, escape behavior; E: less than ten workers, escape behavior; F: no workers on plant surface.

Feeding behavior of ants was investigated as described previously (Heil et al. 2004). Eight colonies of P. gracilis and 12 colonies of $P$. ferrugineus were offered small items (length 1-2 mm) of dead plant material, boiled egg, insect parts, boiled ham, and food bodies of the same Acacia species but derived from another individual. All items were placed on the rachis or blade of young, food-body producing leaves (ten replicates per type of item and per shrub). These experiments were conducted during the peak ant activity between 10:00 a.m. and noon (LC, unpublished data; see also Raine et al. 2002). Ant behavior was observed until the item was (a) discarded actively from the plant, (b) accepted, i.e., carried into a thorn, or (c) ignored by 20 ants.

Natural abundance of stable isotopes

As a more integrative method to study the nutrition of ant colonies, we compared the natural abundances of stable 
isotopes $\left({ }^{13} \mathrm{C}\right.$ and $\left.{ }^{15} \mathrm{~N}\right)$ in the ants and their respective host plants. We collected samples of adult workers, larvae, and leaves from $A$. hindsii plants ( $n=21$ for $P$. ferrugineus and $n=29$ for $P$. gracilis), placed them in microporous capsules, and dried them immediately over silica gel. Samples were transported to Germany, redried until constant weight at $70^{\circ} \mathrm{C}$, finely ground, and weighed into tin capsules $(0.7-$ $2 \mu \mathrm{g}$ ). Analysis of abundances of ${ }^{13} \mathrm{C}$ and ${ }^{15} \mathrm{~N}$ was conducted using a stable isotope ratio mass spectrometer (Finnigan Delta $+\mathrm{XL}$ ) coupled online with a carbon-hydrogen-nitrogen combustion unit (CE 1110) using a ConFlo III open split interface (Werner et al. 1999). Absolute amounts of the heavy stable isotopes are extremely low and thus cannot be reliably quantified. Quantities of stable isotopes in the samples are therefore determined as the ratio $R$ of heavy to light isotopes $\left({ }^{13} \mathrm{C} /{ }^{12} \mathrm{C}\right.$ and $\left.{ }^{15} \mathrm{~N} /{ }^{14} \mathrm{~N}\right)$ and then compared to element-specific standards Vienna Pee Dee Belemnite (VPDB) for $\mathrm{C}$ and $\mathrm{N}_{2}$ in atmospheric air for $\mathrm{N}$ (Peterson and Fry 1987). The results are reported as abundance " $\delta X$ [\%o]" where $\delta X=\left[\left(R_{\text {sample }} / R_{\text {standard }}\right)-1\right] \times 1,000$. The anchor to the international VPDB scale was NBS22 with an assigned value of $-29.78 \%$, the $\delta^{15} \mathrm{~N}$ scale was anchored using IAEA$\mathrm{N} 1$ with an assigned $\delta^{15} \mathrm{~N}$ of $+0.43 \%$. All measurements were calibrated against working reference materials cocombusted within the same measurement sequence ("IT principle"; Werner and Brand 2001).

\section{Allocation to ant reproduction}

Colony sizes and ratios of alates to workers were characterized for 11 colonies each of $P$. gracilis and $P$. ferrugineus. Only colonies that exclusively inhabited a single plant were chosen. Plants were $0.90-1.70-\mathrm{m}$ high and had one clearly dominant main shoot and twigs of maximally the second order. Plants were cut into pieces of $20-30-\mathrm{cm}$ length and put into plastic bags with ether. Bags were kept closed for at least 10 min and the contents of all thorns were then collected in $70 \%$ ethanol, transported to Germany, and counted using a binocular microscope separately for larvae (four stages separated according to size and structure), pupae, workers, and alates. Larvae of alates and workers could only be distinguished for the last three stages of larvae and pupae.

\section{Direct interactions among ant species}

Though colonies of $P$. ferrugineus and $P$. gracilis sometimes occur on the same shrub, direct interactions among workers were rarely observed. The two species usually were spatially separated (i.e., small colonies inhabiting distant twigs), and $P$. gracilis generally actively avoids encounters with other animals by, e.g., moving to the opposite side of the twig. Direct encounters between workers were therefore experimentally provoked by transferring single workers from an $A$. hindsii plant exclusively inhabited by one species to a plant exclusively inhabited by the other species. A total of 50 workers of each species were transferred among ten plants (five workers per colony) and their behavior was observed for the next 5 min or until they left the plant or were killed by the resident ants.

To further assess whether $P$. gracilis prevents plants from being colonized by the mutualist, we collected founding queens of $P$. ferrugineus that had newly entered thorns in September 2005. These queens were placed on ant-free plants, plants inhabited by $P$. ferrugineus, or plants inhabited by $P$. gracilis. We then observed for $30 \mathrm{~min}$ whether queens were attacked, stayed on, or left the plant.

\section{Statistics}

Statistical tests were conducted using Statistical Package for the Social Sciences (SPSS) version 15.0 (SPSS Inc.) and were selected according to the respective experimental design and data structure. Non-parametric tests were applied whenever the data did not fit the assumptions made by the respective parametric tests in order to base the conclusions drawn on conservative estimates of significance.

\section{Results}

Ant occupancy of Acacia plants and behavioral observations

At our field sites, many myrmecophytic Acacia plants hosted colonies of ant species not belonging to the $P$. ferrugineus group. These ants often occupied only small parts of large plants that were not visited by the resident mutualist colony. However, $P$. gracilis was particularly common, occupying $26 \%$ of $A$. hindsii plants $(n=60), 44 \%$ of A. chiapensis ( $n=115), 2 \%$ of the A. cornigera $(n=89)$, and $4 \%$ of $A$. collinsii $(n=52)$.

Many saplings of $<1-\mathrm{m}$ height hosted small colonies of more than one species of Pseudomyrmex on separate branches. Overall, we observed P. ferrugineus, Pseudomyrmex peperi, $P$. gracilis, Pseudomyrmex mixtecus, and $P$. nigropilosus (determined following Ward 1993) on young plants of $A$. hindsii. Founding queens occurred mainly in September and October and occasionally patrolled plant surfaces at high numbers, including one observation of approximately 30 queens of four Pseudomyrmex species on one sapling of $50-\mathrm{cm}$ height without obvious aggressive behavior. Larger colonies of $P$. ferrugineus usually dominate their host plants, but $P$. gracilis and other ant species from different genera can inhabit the lowest parts of the trunk and the lowest major branches of plants $>4 \mathrm{~m}$ high. 
Only on shrubs $0.5-2-\mathrm{m}$ tall were $P$. gracilis colonies ever the only inhabitant observed.

$P$. gracilis queens were regularly found in freshly opened thorns during September 2005 and twice were observed gnawing an entrance hole into a young thorn. Workers of $P$. gracilis were also observed to open new thorns, and, in fact, entrance holes on plants inhabited by $P$. gracilis have a shape different from holes in thorns inhabited by $P$. ferrugineus. Though both $P$. gracilis and $P$. ferrugineus workers leave their host plant, only $P$. gracilis workers were observed to carry off items from the host into thorns.

\section{Effect of occupancy on plant condition}

The ant species inhabiting a plant was significantly associated with the respective plant's condition (Fig. 1a): $A$. hindsii plants inhabited only by $P$. gracilis had significantly more dead shoot tips $(p<0.001$, Wilcoxon pair test, $n=34$ plant pairs), a higher degree of herbivory $(p<0.001$, Wilcoxon pair test, $n=34$ plant pairs), and a higher degree of overgrowth $(p<0.001$, Wilcoxon pair test, $n=34$ plant pairs) than plants inhabited only by $P$. ferrugineus. Relative growth rates decreased significantly with relative degree of dominance by $P$. gracilis (linear regression, $\operatorname{Ln}($ relative growth rate $)=0.75-0.98 / D_{\text {diff }}$, $\left.F_{36,1}=9.3, p=0.004, R^{2}=0.21\right)$. Log transformation of the response variable did not entirely remove heteroscedasticity from the dataset, so we confirmed the robustness of this result by re-running the analysis without five influential data points that had the lowest $D_{\text {diff }}$ values and which accounted for most of the heteroscedasticity (linear regression, $\operatorname{Ln}\left(\right.$ relative growth rate) $=0.68-1.12 / D_{\text {diff, }} F_{31,1}=6.4$, $p=0.014, R^{2}=0.17$ ). The raw relationships between relative growth rate and degree of dominance for both ant species are shown in Fig. $1(b, c)$.

Defensive and feeding behavior of ants

P. ferrugineus and $P$. gracilis differed significantly in their distributions of defensive behaviors (Fig. 2; contingency table test, Pearson's $\left.\chi^{2}=159.1, d f=5, p<0.001\right)$. The majority of $P$. ferrugineus colonies exhibited highly aggressive behavior, with ants active on more than $50 \%$ of leaves in response to artificial disturbance $(>60 \%$ of colonies in categories A and B). In contrast, P. gracilis workers always fled from disturbance and no more than one worker was ever observed on the surface of disturbed plants (categories $\mathrm{E}$ and $\mathrm{F}$ ).

The two ant species also clearly differed in their behavior toward foreign material (Fig. 3). P. ferrugineus actively discarded $>90 \%$ of all items, except food bodies, of which some $80 \%$ were accepted (see Fig. 3a). In contrast, $P$. gracilis accepted ham, egg, and insect parts in over $80 \%$ of

\section{a}

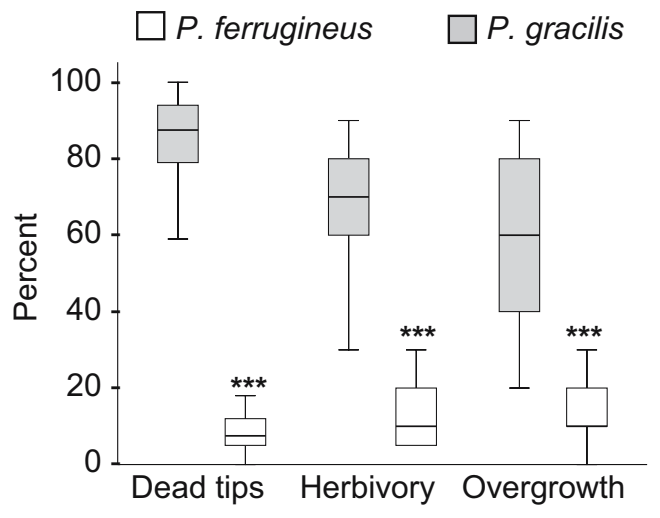

b
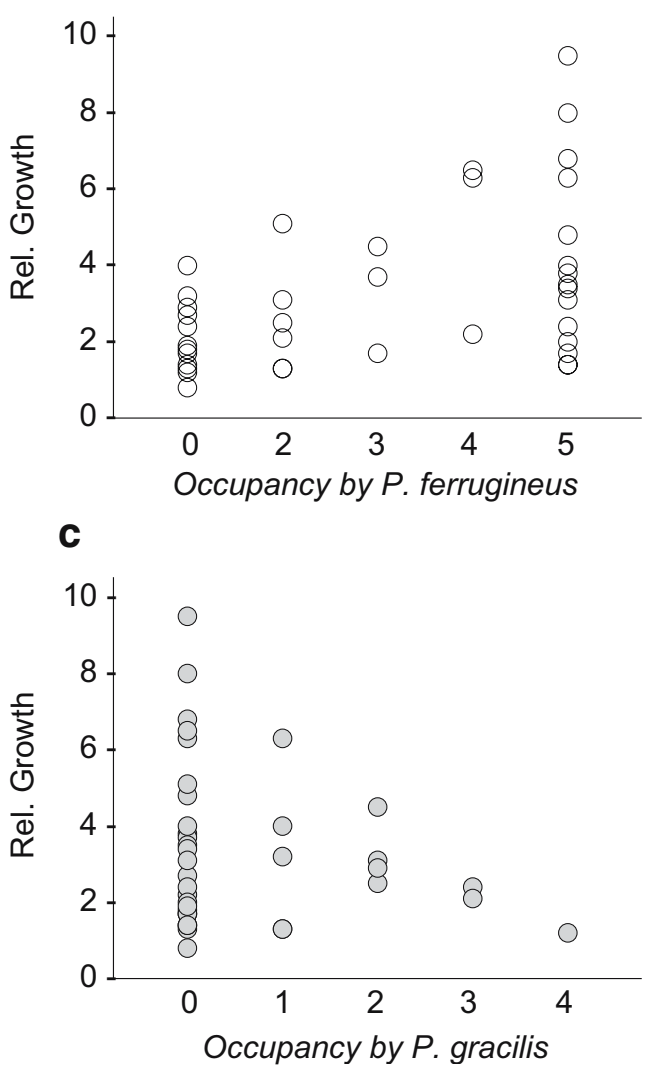

Fig. 1 Effect of occupancy by $P$. gracilis or mutualistic ants on condition and growth of Acacia hindsii. a The current condition of the plant was estimated as percentage of shoot tips destroyed by herbivores, leaf area missing or destroyed as consequence of herbivory, and degree of being overgrown by competing vegetation and is given separately for plants inhabited by $P$. ferrugineus or $P$. gracilis. Significant differences are marked with three asterisks $(p<$ 0.001 , Wilcoxon test on $n=34$ pairs), upper and lower margins of boxes present $25 \%$ and $75 \%$ percentiles, whiskers present $5 \%$ and $95 \%$ percentiles, lines in boxes $=$ medians. Relative growth rates from September 06 through February 07 in dependency of occupation by $P$. ferrugineus (b) and P. gracilis (c) in the beginning of the survey are displayed as relative increase in total shoot length. See "Materials and methods" for categories of occupancy 


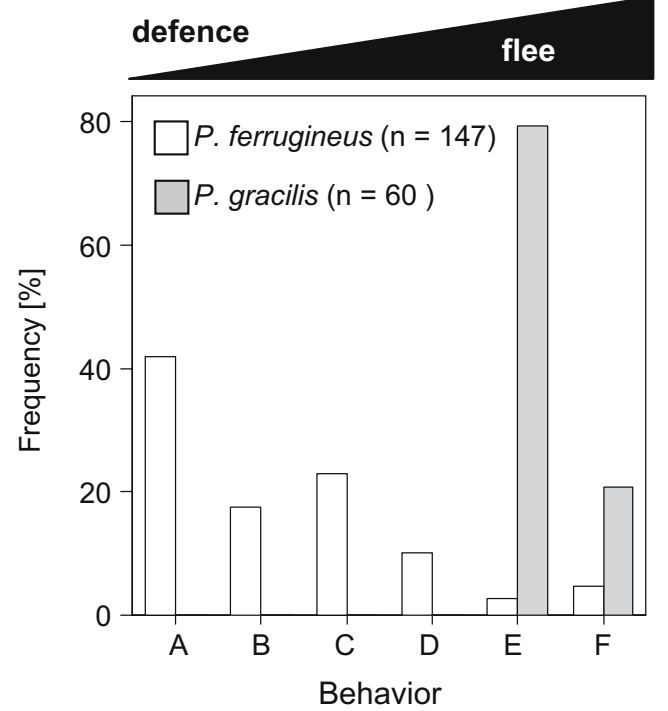

Fig. 2 Behavioral response of ants to simulated attack. Behavior of workers after challenging the plant surface with tweezers was characterized in six categories that are presented here with decreasing level of defensiveness from A to F. Bars represent relative proportion of colonies of each species denoted to the respective category of behavior

cases and always accepted food bodies, while dead plant material was ignored in $>95 \%$ of cases (Fig. 3b). These differences in behavior were highly significant $(p<0.001$ for all items; Pearson's $\chi^{2}$ values: food bodies $\chi^{2}=17.3, d f=1$; egg $\chi^{2}=141.3, d f=2$; insect parts $\chi^{2}=180.9, d f=2$, ham $\chi^{2}=191.9, d f=2$; straw $\chi^{2}=183.7, d f=1$ ).

Natural abundance of stable isotopes

Stable isotope analyses demonstrated a higher proportion of host-independent food sources in the diet of $P$. gracilis as compared to $P$. ferrugineus; natural abundances of ${ }^{15} \mathrm{~N}$ and ${ }^{13} \mathrm{C}$ in workers and larvae of $P$. gracilis differed significantly in all cases from the respective host plant, while for $P$. ferrugineus only $\delta^{15} \mathrm{~N}$ in adult ants differed significantly from the host leaves (Fig. 4). In detail, $\delta^{15} \mathrm{~N}$ values were significantly different among adult workers, brood, and host plant leaves (general linear model: $F_{127,2}=20.0, p<0.001$ ) but not between ant species $\left(F_{127,1}=0.3, p=0.583\right)$, with a significant material $\times$ ant species interaction $\left(F_{127,2}=3.7\right.$, $p=0.026$ ). This interaction was significant because $\delta^{15} \mathrm{~N}$ values in the three types of $P$. gracilis material (adult workers, larvae, and leaves) all differed significantly from each other, but $\delta^{15} \mathrm{~N}$ values in P. ferrugineus larvae did not differ significantly from adult workers nor from leaves (Fig. 4a; least significant difference (LSD) post hoc tests for $P$. gracilis: mean difference between workers and larvae 1.182, $p<0.001$; mean difference between workers and leaves $=2.556, p<0.001$; mean difference between workers and leaves $=1.374, p<0.001$; for $P$. ferrugineus: mean difference between larvae and adult workers $=0.422, p=$
0.409; mean difference between larvae and leaves $=0.592$, $p=0.266$ ). Similarly, $\delta^{13} \mathrm{C}$ differed significantly among $P$. gracilis workers, larvae, and host plants but not for $P$. ferrugineus (Fig. 4b; general linear model: ant species $F_{21,1}=1.0, p=0.312$; material: $F_{21,1}=4.7, p=0.020$; ant species $\times$ material interaction $F_{21,2}=3.6, p=0.046$.)

Colony size and proportion of alates

Although colonies were collected on plants of similar sizes, $P$. ferrugineus colonies contained a median of 300 adult workers (upper quartile 461, lower quartile 160), while $P$. gracilis colonies consisted only of approximately 80 adults (upper quartile 106, lower quartile 55; Mann-Whitney $U$ $6.00, n=11$ per species, $p<0.001)$. The two species also significantly differed in the numbers of larvae and pupae ( $P$. ferrugineus: median 520, upper quartile 865 , lower quartile 222; P. gracilis: median 210, upper quartile 389, lower quartile 88, Mann-Whitney $U$ 22.00, $n=11, p=0.01$ ). Most importantly, allocation to reproduction was significantly higher in $P$. gracilis as, on average, $16.2 \%$ of adult individuals in a $P$. gracilis colony were alates, in contrast

\section{a $P$. ferrugineus}

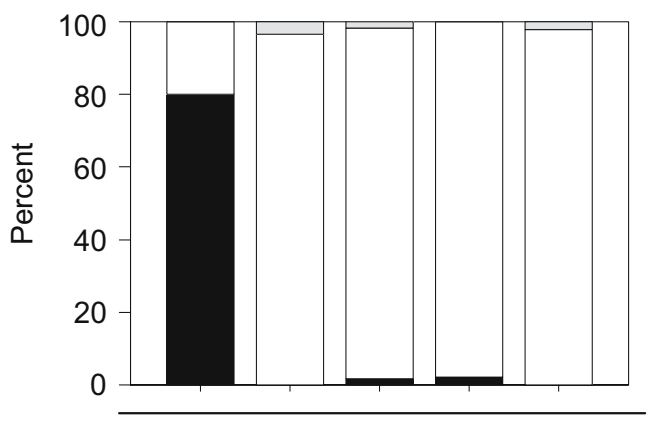

b $P$. gracilis

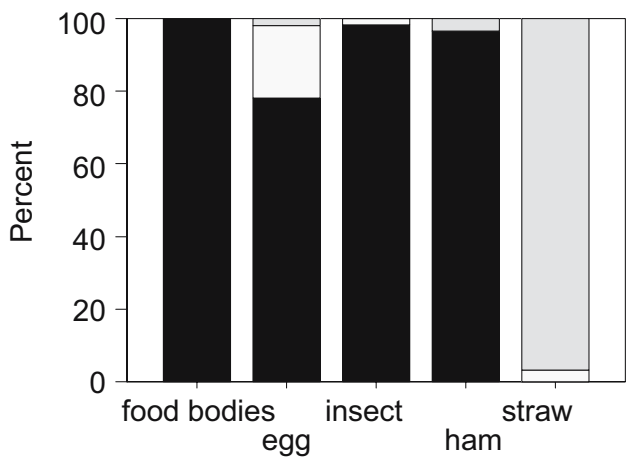

accepted

discarded

ignored

Fig. 3 Behavioral response of ants to different items placed on plant surface. The average percentages in the response of different ant colonies to items offered are given separately for $P$. ferrugineus (a, 12 colonies) and P. gracilis (b, eight colonies) 


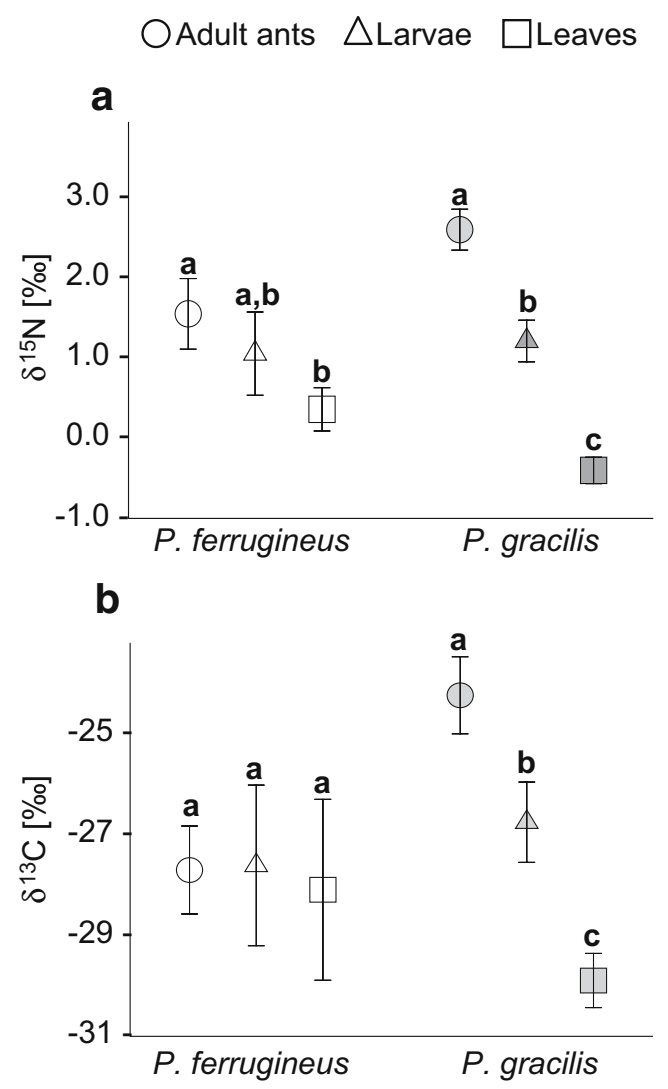

Fig. 4 Natural abundances of stable isotopes. Mean \pm SE of abundances of $\delta^{15} \mathrm{~N}$ (a) and of $\delta^{13} \mathrm{C}(\mathbf{b})$ are displayed in per mil [\%]. Sample sizes for $\mathrm{N}$ are $n=21$ plants with $P$. ferrugineus and $n=$ 29 plants with $P$. gracilis, sample sizes for $\mathrm{C}$ are $n=6$ for both ant species. Material types marked with different letters are significantly different within ant species $(p<0.05$ according to post hoc LSD test)

to $2.0 \%$ for $P$. ferrugineus (Mann-Whitney $U$ 26.5, $n=11$ per species, $p=0.023$; Fig. 5).

Interactions among ants and colony founding

P. gracilis workers are only conditionally aggressive, while P. ferrugineus workers are always so. $P$. gracilis workers on

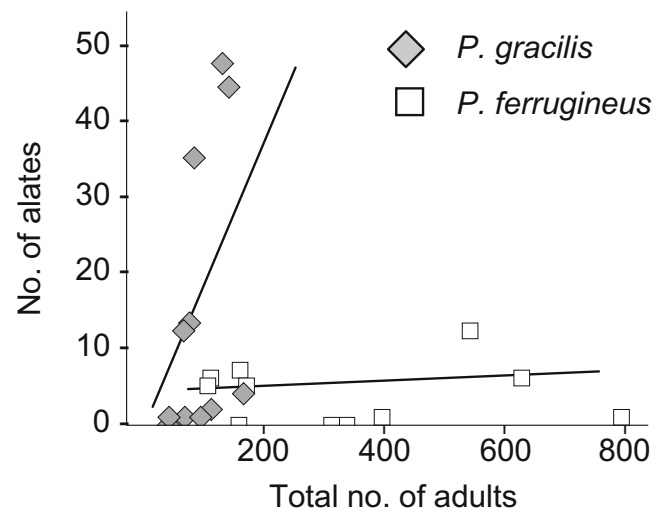

Fig. 5 Number of alates in relation to colony size. Numbers of alates and of all individuals (adults only) are displayed separately for the two ant species investigated. . gracilis: $R=0.42 ; P$. ferrugineus: $R=0.02$, $n=11$ colonies per species their own host plants successfully attacked and killed $P$. ferrugineus workers (39/50 trials); but when $P$. gracilis workers were placed on $P$. ferrugineus-inhabited host plants, $P$. gracilis workers engaged in evasive behavior, usually avoided detection (28/50), and always successfully avoided being killed (0/50 trials). As a result, $P$. gracilis workers were significantly more likely to escape attack when placed on $P$. ferrugineus-inhabited plants $(50 / 50$ trials) than were $P$. ferrugineus workers placed on $P$. gracilis-inhabited plants (11/50 trials; Pearson chi-square $\left.\chi^{2}(d f=1)=63.93, p<0.001\right)$.

The length of time that $P$. ferrugineus founding queens stayed on the plant was significantly affected by whether or not the plant was inhabited by resident ants, while the two species ( $P$. ferrugineus and $P$. gracilis) had very similar effects (Fig. 6). When no ants were present, half of the queens still remained on the plant at the end of the observational period (30 min). In contrast, queens placed on plants with $P$. ferrugineus or $P$. gracilis were on average expelled after less than 2 min with no difference being detected between these two species (general linear model: $F_{21,2}=50.1, p<0.001$; LSD post hoc analysis: mean difference between empty plants and plants with $P$. ferrugineus $=1,431.6 \mathrm{~s}, p<0.001$; mean difference between empty and $P$. gracilis $=1,318.6 \mathrm{~s}, p<0.001$; mean difference between $P$. gracilis and P. ferrugineus $=113.0 \mathrm{~s}, p=0.486$ ).

\section{Discussion}

We studied behavioral and life history traits of a putatively parasitic and a mutualistic ant species. P. gracilis exploited host plant resources (food and nesting space provided by Acacia hosts) though it was found to depend less on host-

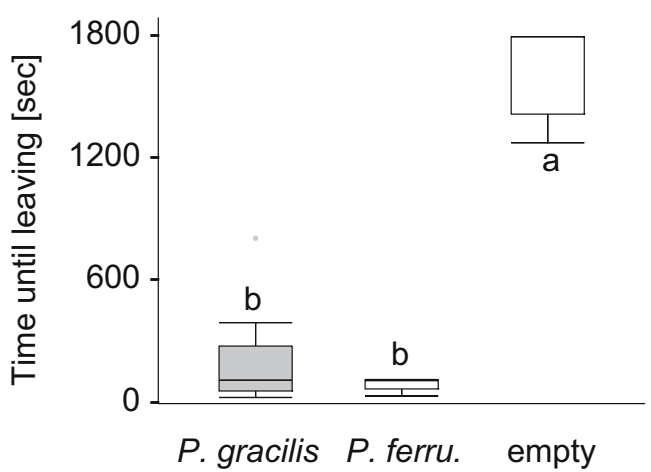

Fig. 6 Aggressive behavior of resident ants toward founding queens. The average time [s] that founding queens placed on inhabited plants stayed on the plant until they were attacked and expelled by the resident ants is given for ant-free plants ("empty", $n=8$ ), plants inhabited by $P$. ferrugineus $(n=7)$ and P. gracilis $(n=8)$. Different letters indicate significant differences $(p<0.001$ according to LSD post hoc test after univariate ANOVA). Upper and lower margins of boxes present $25 \%$ and $75 \%$ percentiles, whiskers present $5 \%$ and $95 \%$ percentiles, lines in boxes are medians 
derived food sources than the mutualist, $P$. ferrugineus. As being inhabited by $P$. gracilis negatively affected host plant state and growth rate and as this ant can exclude the mutualist from colonization, we conclude that $P$. gracilis is a parasite of the mutualism between Acacia myrmecophytes and ants of the $P$. ferrugineus group. Both species are congeneric and inhabit the same hosts, which largely rules out different environments and phylogenetic histories as the causes for their different ecological lifestyles. Instead, the reduced dependence on host-derived resources, the smaller colony sizes, and the higher allocation to alates in $P$. gracilis likely represent adaptations to this particular lifestyle and suggest some candidate traits that could generally characterize parasites of mutualisms.

The differences in host plant condition could be explained by the two ant species' behavior. Mutualistic $P$. ferrugineus ants were more active on the plant surface and more aggressive than workers of $P$. gracilis, which usually move to the opposite side of the leaf or twig when facing larger intruders (LC, personal observations). Items not accepted as food sources were ignored by $P$. gracilis rather than discarded from the plant, as regularly observed for mutualistic plant-ants (Janzen 1974; Davidson et al. 1988; Fiala et al. 1989; Fiala and Maschwitz 1990; Heil and McKey 2003). In all these traits, $P$. gracilis is similar to other non-protecting parasites of ant-plant mutualisms, such as $P$. nigropilosus (Janzen 1975), Cataulacus mckeyi (Gaume and McKey 1999), or C. planatus (Raine et al. 2004).

However, any ant species that forages for insects shoulddue to its mere presence - reduce herbivory on an inhabited plant as compared to a completely predator-free one (Heil and McKey 2003). It is therefore a matter of discussion whether or not a species that provides a lower-but not zero-service can be regarded as parasite of a mutualism. In fact, hosts often can be inhabited by several species of partners that differ in the quality of service they provide. Cases for which this has been described comprise, besides ant-plant mutualisms (Izzo and Vasconcelos 2002; Feldhaar et al. 2003; Bruna et al. 2004; Tillberg 2004; Frederickson 2005; Gaume et al. 2005a, b), very different types of interactions such as symbioses between plant roots and rhizobial bacteria (West et al. 2002; Denison and Kiers 2004) and between roots and mycorrhizal fungi (West et al. 2002; Sanders 2004). While Feldhaar et al. (2003) reported a "succession" of ant species on some Macaranga species but did not find a regular parasite, Raine et al. (2004) found C. planatus ants to actively exclude workers of $P$. ferrugineus from extrafloral nectaries of Acacia mayana and therefore defined this species as a parasite. Similarly, Ferrière et al. (2007) stated that a true parasite of the mutualism should exclude the mutualist, a phenomenon that indeed was found in our study: $P$. gracilis workers specifically attacked $P$. ferrugineus workers and queens when encountered on their plant. In summary, P. gracilis can impose severe opportunity costs on the plant by actively preventing the establishment of the protective mutualism and thus indeed can be termed a parasite of the ant-Acacia mutualism (Yu and Pierce 1998; Yu 2001; Ferrière et al. 2007).

How can $P$. gracilis survive on Acacia myrmecophytes that so obviously suffer from its presence (Fig. 1c)? When offered putative external food sources, $P$. ferrugineus ants only accept Acacia food bodies (Heil et al. 2004). In contrast, $P$. gracilis accepted external protein sources such as pieces of ham, egg, and dead insects almost as often as food bodies. These differences in food resource utilization are reflected in the digestive capacities of the two ant species (Heil et al. 2005) and were confirmed by natural abundances of stable isotopes. Stable isotopes have been used to study nutrient fluxes among ant plants and their ants (Sagers et al. 2000; Fischer et al. 2002), thereby for instance defining differences between mutualistic and supposedly parasitic ants (Tillberg 2004). In the present study, $\delta^{13} \mathrm{C}$ and $\delta^{15} \mathrm{~N}$ in $P$. gracilis ants (workers and larvae) were significantly higher than in the respective host plants, which indicate that the body tissue of larvae and workers contained non-host material. In contrast, no such differences were found for P. ferrugineus; hence, the entire body tissue of these ants was derived from host material. The magnitudes of differences among plant and consumers as found in our study are surprisingly low, as usually the step of one trophic level is characterized by an increase in $\delta^{15} \mathrm{~N}$ of 3.4\% (Post 2002; Thompson et al. 2005). Similarly, low differences in natural abundances of stable isotopes between presumed food source and ant also characterize the Cecropia-Azteca symbiosis and were interpreted as a result of nutrient fluxes from the ant back to the plant (Sagers et al. 2000). It remains to be tested whether such nutrient fluxes can also be found in the Acacia-Pseudomyrmex mutualism. However, and most importantly in the context of the present study, our results demonstrate that $P$. gracilis is nutritionally less dependent on its host plant than is $P$. ferrugineus.

Further adaptations to these different lifestyles were investigated at the level of colony size and allocation to reproduction. $P$. gracilis produced much smaller colonies with a higher proportion of alates than did P. ferrugineus, and alates appeared in smaller colonies of $P$. gracilis, relative to P. ferrugineus. Similar patterns characterize the MacarangaCrematogaster system, where "early successional" ant species produced alates at smaller colony sizes than did "late successional" species (Feldhaar et al. 2003). Such differences in alate allocation might be an artifact of sampling outside $P$. ferrugineus' reproductive peak. However, observations over several years have found that the highest numbers of founding queens of both species occur in September and October (LC and $\mathrm{MH}$, personal observations). 
To generalize our findings to cooperation theory, we note that $P$. gracilis' reduced reliance on host resources reduces the correlation between host fitness and symbiont fitness (Sachs et al. 2004). As a result, $P$. gracilis' fitness should be less adversely affected by the loss of host plant tissue than is $P$. ferrugineus' fitness, and if $P$. gracilis gains more total fecundity by avoiding investment in patrolling workers than it loses by living in a smaller and more rapidly dying plant, non-patrolling behavior can be maintained (Edwards et al. 2006). Hence, the parasitic lifestyle in P. gracilis is to reproduce early and therefore at small colony sizes (an " $r$ like" strategy), giving it more opportunity to have colonized new hosts when its old host dies.

Many mutualisms consist of groups of interacting species with different degrees to specialization to the host, including exploiters. Thus, the traits documented here might also characterize other parasites of mutualisms. For example, of the strains of Rhizobia bacteria that infect plant roots, some establish a mutualistic symbiosis by starting nitrogen fixation, while other strains do not and therefore parasitize the system (Kiers et al. 2003; Denison and Kiers 2004). Host sanctions against non-fixing strains and strikingly different reproduction maintenance trade-offs led to well-defined life history characteristics that differ according to the respective strategies and that allow a cooccurrence of these different strategies (West et al. 2002; Denison and Kiers 2004). Though our study system consists of only two ant species, it thus appears likely that the results of the present study can be broadly applied, i.e., that $r$-like strategies in general characterize parasites of mutualists.

Acknowledgements We are grateful to Judy Bronstein, Brigitte Fiala, and Douglas Yu for many thoughtful comments on earlier versions of this manuscript and to Douglas Yu for helping with the statistics and the English. Special thanks are to Juan Carlos Silva Bueno for field assistance and to Heike Geilmann (Berkeley Geochronology Center IsoLab Jena) for performing the routine isotope ratio analyses for this study. Financial support by the Deutsche Forschungsgemeinschaft (grant He 3169/4-2) and the Max Planck Society for the Advancement of Science is gratefully acknowledged. The experiments presented here comply with the current laws of Mexico and Germany.

\section{References}

Bronstein JL (1994) Our current understanding of mutualism. Quart Rev Biol 69:31-51

Bronstein JL (1998) The contribution of ant-plant protection studies to our understanding of mutualism. Biotropica 30:150-161 DOI 10.1111/j.1744-7429.1998.tb00050.x

Bronstein JL (2001) The exploitation of mutualisms. Ecol Lett 4:277287 DOI 10.1046/j.1461-0248.2001.00218.x

Bruna EM, Lapola DM, Vasconcelos HL (2004) Interspecific variation in the defensive responses of obligate plant-ants: experimental tests and consequences for herbivory. Oecologia 138:558-565 DOI 10.1007/s00442-003-1455-5

Buschinger A, Heinze J, Jessen K, Douwes P, Winter U (1987) First European record of a queen ant carrying a mealybug during her mating flight. Naturwissenschaften 74:139-140 DOI 10.1007/ BF00366526

Clark JW, Hossain S, Burnside CA, Kambhampati S (2001) Coevolution between a cockroach and its bacterial endosymbiont: a biogeographical perspective. Proc Roy Soc Lond B 268:393-398

Davidson DW, Longino JT, Snelling RR (1988) Pruning of host plant neighbors by ants: an experimental approach. Ecology 69:801808

Denison RF, Kiers ET (2004) Lifestyle alternatives for rhizobia: mutualism, parasitism, and forgoing symbiosis. FEMS Microbiol Lett 237:187-193

Edwards DP, Hassall M, Sutherland WJ, Yu DW (2006) Selection for protection in an ant-plant mutualism: host sanctions, host modularity and the principal-agent game.Proc Roy Soc Lond B 273: 595- 602 (DOI 10.1098/rspb.2005.3273)

Feldhaar H, Fiala B, Hashim Rb, Maschwitz U (2003) Patterns of the Crematogaster-Macaranga association: the ant partner makes the difference. Insect Soc 50:9-19

Ferrière R, Gauduchon M, Bronstein JL (2007) Evolution and persistence of obligate mutualists and exploiters: competition for partners and evolutionary immunization. Ecol Lett 10:115126 DOI 10.1111/j.1461-0248.2006.01008.x

Fiala B, Maschwitz U (1990) Studies on the South East Asian antplant association Crematogaster borneensis/Macaranga: adaptations of the ant partner. Insect Soc 37:212-231

Fiala B, Maschwitz U, Tho YP, Helbig AJ (1989) Studies of a South East Asian ant-plant association: protection of Macaranga trees by Crematogaster borneensis. Oecologia 79:463-470

Fischer RC, Richter A, Wanek W, Mayer V (2002) Plants feed ants: food bodies of myrmecophytic and their significance for the interaction with Pheidole bicornis ants. Oecologia 133: 186-192 (DOI 10.1007/s00442-002-1000-y)

Frederickson ME (2005) Ant species confer different partner benefits on two neotropical myrmecophytes. Oecologia 143:387-395 DOI 10.1007/s00442-004-1817-7

Gaume L, McKey D (1999) An ant-plant mutualism and its hostspecific parasite: activity rhythms, young leaf patrolling, and effects on herbivores of two specialist plant-ants inhabiting the same myrmecophyte. Oikos 84:130-144

Gaume L, Zacharias M, Borges RM (2005a) Ant-plant conflicts and a novel case of castration parasitism in a myrmecophyte. Evol Ecol Res 7:435-452

Gaume L, Zacharias M, Grosbois V, Borges RM (2005b) The fitness consequences of bearing domatia and having the right ant partner: experiments with protective and non-protective ants in a semi-myrmecophyte. Oecologia 145:76-86

Heil M, Baumann B, Krüger R, Linsenmair KE (2004) Main nutrient compounds in food bodies of Mexican Acacia ant-plants. Chemoecology 14:45-52 DOI 10.1007/s00049-003-0257-x

Heil M, McKey D (2003) Protective ant-plant interactions as model systems in ecological and evolutionary research. Annu Rev Ecol Evol Syst 34:425-453 DOI 10.1146/annurev.ecolsys.34.011802.132410

Heil M, Rattke J, Boland W (2005) Post-secretory hydrolysis of nectar sucrose and specialization in ant/plant mutualism. Science 308:560-563 DOI 10.1126/science.1107536

Hoeksema JD, Bruna EM (2000) Pursuing the big questions about interspecific mutualism: a review of theoretical approaches. Oecologia 125:321-330 DOI 10.1007/s004420000496

Izzo TJ, Vasconcelos HL (2002) Cheating the cheater: domatia loss minimizes the effects of ant castration in an Amazonian ant-plant. Oecologia 133:200-205 DOI 10.1007/s00442-002-1027-0 
Janzen DH (1966) Coevolution of mutualism between ants and acacias in Central America. Evolution 20:249-275

Janzen DH (1974) Swollen-thorn acacias of Central America, vol 13. Smithsonian Institution, Washington, DC

Janzen DH (1975) Pseudomyrmex nigropilosa: a parasite of a mutualism. Science 188:936-937 DOI 10.1126/science.188.4191. 936

Kiers ET, Rousseau RA, West SA, Denison RF (2003) Host sanctions and the legume-rhizobium mutualism. Nature 425:78-81 DOI 10.1038/nature01931

Klein RW, Kovac D, Schellerich A, Maschwitz U (1992) Mealybugcarrying by swarming queens of a southeast asian bambooinhabiting ant. Naturwissenschaften 79:422-423 DOI 10.1007/ BF01138577

Peterson BJ, Fry B (1987) Stable isotopes in ecosystem studies. Annu Rev Ecol Syst 18:293-320

Post DM (2002) Using stable isotopes to estimate trophic position: models, methods, and assumptions. Ecology 83:703-718

Raine NE, Gammans N, Macfadyen IJ, Scrivner GK, Stone GN (2004) Guards and thieves: antagonistic interactions between two ant species coexisting on the same ant-plant. Ecol Entomol 29:345-352 DOI 10.1111/j.0307-6946.2004.00608.x

Raine NE, Willmer P, Stone GN (2002) Spatial structuring and floral avoidance behavior prevent ant-pollinator conflict in a Mexican ant-acacia. Ecology 83:3086-3096

Sachs JL, Mueller UG, Wilcox TP, Bull JJ (2004) The evolution of cooperation. Q Rev Biol 79:135-160

Sagers CL, Ginger SM, D Evans R (2000) Carbon and nitrogen isotopes trace nutrient exchange in an ant-plant mutualism. Oecologia 123:582-586

Sanders IR (2004) Plant and arbuscular mycorrhizal fungal diversityare we looking at the relevant levels of diversity and are we using the right techniques. New Phytol 164:415-418

Sauer C, Stackebrandt E, Gadau J, Holldobler B, Gross R (2000) Systematic relationships and cospeciation of bacterial endosymbionts and their carpenter ant host species: proposal of the new taxon Candidatus Blochmannia gen. nov. Int J Syst Evol Microbiol 50:1877-1886

Skwarra E (1935) Ökologie der Lebensgemeinschaften mexikanischer Ameisenpflanzen. Z Morphol Ökol Tiere 29:306-373

Stanton ML (2003) Interacting guilds: moving beyond the pairwise perspective on mutualisms. Am Nat 162:S10-S23
Stanton ML, Palmer TM, Young TP, Evans A, Turner ML (1999) Sterilization and canopy modification of a swollen thorn acacia tree by a plant-ant. Nature 401:578-581 DOI 10.1038/44119

Thompson DR, Bury SJ, Hobson KA, Wassenaar LI, Shannon JP (2005) Stable isotopes in ecological studies. Oecologia 144:517-519

Tillberg CV (2004) Friend or foe? A behavioral and stable isotopic investigation of an ant-plant symbiosis. Oecologia 140:506-515 DOI 10.1007/s00442-004-1601-8

Ward PS (1993) Systematic studies on Pseudomyrmex acacia-ants (Hymenoptera: Formicidae: Pseudomyrmecinae). J Hym Res 2:117-168

Ward PS, Downie DA (2005) The ant subfamily Pseudomyrmecinae (Hymenoptera: Formicidae): phylogeny and evolution of bigeyed arboreal ants. Syst Entomol 30:310-335

Werner RA, Brand WA (2001) Referencing strategies and techniques in stable isotope ratio analysis. Rapid Commun Mass Spectrom 15:501-519

Werner RA, Bruch BA, Brand WA (1999) ConFlo III-an interface for high precicion $\delta^{13} \mathrm{C}$ and $\delta^{15} \mathrm{~N}$ analysis with an extended dynamic range. Rapid Commun Mass Spectrom 13:1237-1241

West SA, Kiers ET, Pen I, Denison RF (2002) Sanctions and mutualism stability: when should less beneficial mutualists be tolerated. J Evol Biol 15:830-837

Wheeler WM (1942) Studies of neotropical ant-plants and their ants. Museum of Comparative Zoology, Harvard College

Wilkinson DM, Sherratt TN (2001) Horizontally acquired mutualisms, an unsolved problem in ecology. Oikos 92:377-384

Yu DW (2001) Parasites of mutualisms. Biol J Linnean Soc 72:529_ 546

Yu DW, Pierce NE (1998) A castration parasite of an ant-plant mutualism. Proc Roy Soc Lond B 265: 375-382 (DOI 10.1098/ rspb.1998.0305)

Yu DW, Wilson HB, Frederickson ME, Palomino W, De La Colina R, Edwards DP, Balareso AA (2004) Experimental demonstration of species coexistence enabled by dispersal limitation. J Anim Ecol 73:1102-1114

Zientz E, Dandekar T, Gross R (2004) Metabolic interdependence of obligate intracellular bacteria and their insect hosts. Microbiol Mol Biol Rev 68:745-770 DOI 10.1128/MMBR.68.4.745-770.2004

Zientz E, Feldhaar H, Stoll S, Gross R (2005) Insights into the microbial world associated with ants. Arch Microbiol 184:199206 DOI 10.1007/s00203-005-0041-0 